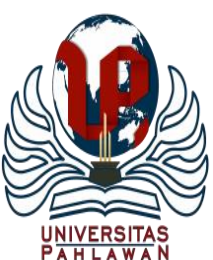

Edukatif : Jurnal Ilmu Pendidikan Volume 3 Nomor 1 Tahun 2021 Halm 144-148

EDUKATIF: JURNAL ILMU PENDIDIKAN

Research \& Learning in Education

https://edukatif.org/index.php/edukatif/index

\title{
Pembelajaran Dengan Kegiatan Daur Ulang Botol Bekas Untuk Anak Usia Dini
}

\author{
Weni Mulia Putri ${ }^{1}$, Rismareni Pransiska²
}

Universitas Negeri Padang ${ }^{1,2}$

e-mail : Wenimuliputri@gmail.com¹, pransiskaunp@fip.unp.ac.id ${ }^{2}$

\begin{abstract}
Abstrak
Kegiatan daur ulang botol bekas dapat dimanfaatkan sebagai pembelajaran untuk anak, yang mana kegiatannya adalah mengolah botol bekas yang sudah tidak terpakai menjadi suatu karya yang inovatif Penelitian ini dilatarbelakangi oleh pembelajaran dengan menggunakan daur ulang botol bekas untuk anak. Tujuannya adalah untuk menganalisis penggunaan daur ulang botol bekas dapat diubah fungsikan menjadi media pembelajaran untuk anak. Jenis penelitiannya adalah dengan pengambilan data dengan mengkaji jurnal, buku dan artikel sesuai dengan variabel yang diteliti. Hasil studi literatur ini yaitu pengunaan daur ulang botol bekas dapat di jadikan pembelajaran untuk anak usia dini, yang mana dengan pemanfaatan daur ulang botol bekas dapat mengembangkan kemampuan motorik serta seni anak.
\end{abstract}

Kata Kunci: Pembelajaran Anak Usia Dini, Daur Ulang Botol Bekas

\begin{abstract}
Bottle recyling activities can be used as a learning for child. The activity is to process used bottle that are not used into an innovative work. Background of this research are learning for use reycling used bottles for early childhood eduation. The goal is to Analyze to use of reacycled used bottles that an be converted into learning media for child. The type of research carried out is by taking data from journals, books and articles related to the research conducted by researchers. Results of this literature is show that the used bottle reycling can be used as learning for children, which by used boottle recycling can develop motor skills and children's arts
\end{abstract}

Keywords: Early Childhood Learning, Used Bottle Recyling

Copyright (c) 2021 Weni Mulia Putri, Rismareni Pransiska

$\triangle$ Corresponding author :

Address : -

Email : Wenimuliputri@gmail.com

ISSN 2656-8063 (Media Cetak)

DOI: https://doi.org/10.31004/edukatif.v3i1.269 


\section{PENDAHULUAN}

Pendidikan pada saat usia dini adalah hal terpenting untuk anak, karena pendidikan merupakan dasar dalam pembentukan anak. Sebagaimana menurut Suyadi (2017), mengatakan bahwa pendidikan dilaksanakan untuk memfasilitasi perkembangan dan pertumbuhan anak. Lembaga pendidikan anak adalah Taman KanakKanak (TK). Tujuan dari lembaga TK adalah menyiapkan anak untuk memasuki lembaga selanjutnya.

Prinsip pendidikannya adalah seluruh kegiatan pembelajaran didasari oleh aspek bermain karena sejatinya anak tidak akan lepas dari kata bermain, untuk itu dengan bermain di harapkan mampu memenuhi seluruh perkembangan dan pertumbuhan anak dengan baik. Macam-macam perkembangan anak yaitu pertama kogntif, kedua fisikmotorik, selanjutnya bahasaa, sosial, moral dan seni (Sulaiman et al., 2019). Disni guru memegang peranan penting untuk melakukan pembelajaran dalam menggunakan metode ataupun penggunaan media untuk proses pembelajaran. Agar tujuan pendidikan anak tercapai maksimal.

Penggunaan alat peraga pada saat pembelajaran sangatlah penting karena media dapat memperjelas informasi yang akan diberikan kepada anak. Media yang diberikan di buat dengan kreatif dan inovatif agar dapat menarik perhatian anak. Media pembelajaran terbagi 3 (tiga) yaitu media visual, audio, audio visual (Zaman \& Eliyawati, 2010). Yang mana dalam pengadaan media pembelajaran dapat di lakukan dengan pembelian, menerima sumbangan atau membuatnya sendiri.

Dalam proses pembuatan media pembelajaran dapat dilakukan melalui bahan alami, buatan dan bahan bekas/tidak terpakai. Bahan alami berupa seperti : dedaunan, bunga, ranting, biji-bijian, dll. Bahan buatan seperti : kertas, sabun, lilin, pewarna, dll. Sedangkan bahan bekas seperti : botol plastik, bungkus permen, koran, dll. Guru dituntut untuk kreatif dan inovatif dalam membuat media pembelajaran untuk anak (Agustina et al., 2018). Dalam penelitian ini peneliti menggunakan botol bekas untuk mengembangkan motorik halus anak, botol bekas ialah barang yang dibuang setelah dipakai seperti botol bekas minuman vanta, sprit, dll (Agustina et al., 2018).

Di era modern sekarang ini banyak pendidik yang mengandalkan teknologi untuk mempermudah pekerjaannya tetapi banyak pula yang terlena akan teknologi yang semakin canggih sehingga memuat mereka lupa dengan media-media pembelajaran yang dapat di kembangkan dari lingkungan disekitar (Siarni et al. dalam Nuwairah et al., 2018). Dan juga menurut Dewi (2018), dalam skripsinya yang mengatakan bahwa media modern telah membuat mereka kurang peka terhadap potensi yang ada di sekitar mereka dikarenakan media modern telah membuat mereka tergantung dalam penggunaannya. Sedangkan penggunaan media yang kreatif di Taman Kanak-Kanak sangatlah penting untuk menunjang proses pencapain belajar. Maka dari itu tujuan penelitian ini menganalisis penggunaan daur ulang botol bekas yang dijadikan sebagai kegiatan pembelajaran anak yang bermanfaat untuk pengambangan ilmu pengetahuan dari kegiatan daur ulang botol bekas sebagai kegiatan pembelajaran.

\section{METODE PENELITIAN}

Peneliti menggunakan penelitian studi literatur, penelitian ini dilakukan dengan menelaah jurnaljurnal, buku-buku, artikel-artikel dan skripsi yang selaras dari masalah yang sedang diteliti dan dianalisis secara mendalam (Melfianora dalam Elpia \& Saridewi, 2020). Penelitian studi literatur ini mengutip dari sumber yang terpercaya, yaitu sumber data sekunder yang diperoleh dari mempelajari dan menganalisis data yang bersumber dari literatur yang ada (Sugiyono, 2013).

Teknik penelitian yang peneliti lakukan adalah dengan menggunakan teknik studi literatur yaitu teknik yang mengumpulkan sumber-sumber yang relevan, yang memuat informasi untuk keberlangsungan proses penelitian. Setelah data dikumpulkan selanjutnya dilakukan analisis/diteliti dengan seksama (Kristanto, 2018). Jadi setelah kita memperoleh data selanjutnya adalah melalakukan analisis untuk dapat di organisasikan kedalam kategori-kategori yang relevan serta membuat kesimpulan. 


\section{HASIL DAN PEMBAHASAN PENELITIAN}

\section{Konsep PAUD}

Pendidikan dilakukan dengan tujuan untuk memasilitasi kebutuhan anak secara menyeluruh agar anak siap untuk memasuki jenjang pendidikan berikutnya sejalan dengan pemikiran diatas menurut Suyadi (2017), pendidikan bagi anak adalah yang menekankan pada pengembangan dan pertumbuhan seluruh aspek-aspek anak. prinsip-prinsip pendidikan harus diperhatikan sebelum memberikan pembelajaran yang dilakukan dengan penggunakan konsep pembelajaran yang terpadu dan dilakukan melalui tema dan sub tema dengan memperhatikan kondisi lingkungan sosial budaya dan karakteristik anak. Pembelajaran anak usia dini merupakan kegiatan belajar dan berorientasi pada kebutuhan anak yang di sesuaikan dengan tingkatan usia atau perkembangan anak.

Selanjutnya penggunaan media pembelajaran yang unik dan menarik sangat penting diperhatikan. Media pembelajaran sangat di perlukan dalam melakukan pembelajaran menurut Wahyuni (2018), mengatakan bahwasanya penggunaan media adalah untuk mempermudah anak dalam memahami suatu materi pembelajaran. Tujuan penggunaan media pembelajaran adalah memperjelas penyajian pesan, mengatasi keterbelakangan ruang, mengatasi sifat pasif siswa (Mursid, 2015).

\section{Konsep Pembelajaran Daur Ulang Botol Bekas}

Daur ulang adalah tindakan yang melakukan kegiatan mengolah suatu barang, menurut Anggraeni et al. (2017), mengolah kembali sampah atau reycle menjadi barang yang bermanfaat salah satu nya seperti botol bekas. Botol bekas menurut Agustina et al. (2018), adalah barang bekas yang biasanya disebut dengan sampah yang berupa plastik. Pembelajaran dengan menggunakan botol bekas memberikan dampak yang positi bagi anak usia dini. Zaman \& Eliyawati (2010), mengatakan bahwa pembelajaran bisa dilakukan dengan menggunakan barang bekas. Menurut Nurani (2012), kegiatan daur ulang dapat dijadikan alternatif untuk pembelajaran dalam menunjang perkembangan seni dan motorik halus. Barang bekas seperti botol bekas vanta dapat di ubah menjadi celengan berkarakter lucu menurut (Budiono, 2017).

\section{Pembelajaran dengan Kegiatan Mendaur Ulang Botol Bekas Untuk Anak Usia Dini}

Kegiatan mendaur ulang botol bekas merupakan kegiatan yang melibatkan berbagai aktifitas seperti menggunting, menempel, mengelem, mengecet dan sebagainya. Menurut Wigati \& Wiyani (2020), dalam kegiatan pembelajaran dengan menggunakan botol bekas sebelumnya guru harus menyusun materi kegiatan yang akan disampaikan agar selaras atau relevan dengan tema. Selanjutnya menurut Hanafi \& Sujarwo (2015), mengatakan bahwa botol bekas bisa diubah fungsikan menjadi kegiatan pembelajaran bagi ank untuk meningkatkan seni dan motorik halus.

\section{Analisis dari Hasil Temuan tentang Kegiatan Pembelajaran dengan Botol Bekas untuk Perkembangan Motorik Halus Anak}

Pertama, pendapat Maghfirah (2019), pemanfaatan media dari botol bekas bisa digunakan unuk peningkatan kemampuan motorik halus di TK Wiyata. Dapat dilihat dengan respon anak yang sangat antusis dan bersemangat dalam melakukan kegiatan pengunaan botol bekas menjadi suatu karya yang menarik.

Kedua, pendapat Wahidah \& Erni (2019), pelaksanaan mendaur ulang bahan bekas dikelompok B RA AR-RAFIF nyatanya mampu meningkatkan motorik halus anak. Dalam percobaan pertama kemampuan motorik anak sudah mengalami peningkatan yang memuaskan, jadi dapat dinyatakan bahwa penggunaan botol bekas terbukti efektif untuk anak.

Ketiga, Iriani (2013), mengatakan bahwa bahan bekas dapat berupa botol aqua jika dimanfaatkan akan bisa memacu perkembangan motorik halus anak. Didalam penelitiannya penggunaan botol bekas diiringi dengan penggunaan bahan daur ulang yang lainnya tetapi bahan utamanya tetap menggunakan botol bekas, kegiatannya tersebut memang terbukti untuk kemammpuan motorik halus dari proses pembuatannya.

Analisis dari Hasil Temuan tentang Kegiatan Pembelajaran dengan Botol Bekas untuk Perkembangan Seni Anak 
Pertama, Puspitasari (2018), bahwa terjadi peningkatan nilai yang sangat tinggi pada kelas eksperimenn, jadi terdapat dampak yang tinggi dalam pemanafatan sampah daur ulang terhadap kreatifitas seni pada anak. Hal tersebut terjadi dikarenakan pembelajaran sebelumnya tidak terlalu inovatif ddan anak merasa bosan tetapi saat melakukan kegiatan mengolah botol bekas anak langsung bersemangat dalam mengerjakannya .

Kedua, Fadhila \& Rakimahwati (2020), kegiatan pengolahan daur ulang botol bekas sangat berpengaruh dalam meningkatkan kreativitas seni anak, dilihat dari peningkatan yang pada setelah pembelajaran. Sama halnya dengan penelitian diatas peningkatan yang didapatkan dalam kegiatan daur ulang botol bekas dikarenakan anak merasa kegiatan tersebut sangat menarik karena menggunakan barang-barang yang baru dan hal tersebut menarik perhatian anak.

Ketiga, menurut Mulyati \& Sukmawijaya (2013), penggunaan botol bekas dalam kegiatan pembelajaran di TK sangat berpengaruh signifikan terhadap perkembangan seni anak. Pada dasarnya anak adalah individu yang mudah untuk di arahkan, akan tetapi penggunaan kegiatan botol bekas mendapatkan hasil yang maksimal untuk perkembangan seni anak.

Jadi kedua penjelasan diatas dapat simpulkan bahwa pembelajaran dengan kegiatan mendaur ulang botol bekas menjadi sebuah karya terbukti sangat baik untuk peningkatkan kemampuan motorik halus dan kemampuan seni anak. Penggunaan kegiatan barang bekas bisa menjadikan anak sangat antusias, senang, serta kreatif dan imajinatif oleh sebab itu selama kegiatan berlangsung anak sudah mampu dengan baik mengkoordinasikan mata dan tangan serta dapat mengembangkan kemampuan seninya.

\section{KESIMPULAN}

Mengacu kepada literatur-literatur yang peneliti paparkan di atas didapatkan simpulan bahwasanya kegiatan daur ulang botol bekas sangat efektif untuk dijadikan sebagai kegiatan pembelajaran bagi anak bahkan banyak lagi manfaat dengan dilaksanakannya kegiatan daur ulang botol bekas tersebut diantaranya dapat meningkatkan keterampilan kreativitas seni dan meningkatkan keterampilan motorik halus. Dikarenakan kegiatan mendaur ulang botol bekas sangat menarik bagi anak. Pada saat melakukannya anak merasa senang, antusias, kreatif serta imajinatif. Pembelajaran dengan menggunakan kegiatan daur ulang botol bekas dapat digunakan dalam berbagai tema, tergantung cara guru untuk merancang pembelajaran dengan menggunakan botol bekas tersebut.

\section{DAFTAR PUSTAKA}

Agustina, S., Nasirun, M., \& D, D. (2018). Meningkatkan Keterampilan Motorik Halus Anak Melalui Bermain dengan Barang Bekas. Jurnal Ilmiah Potensia, 3(1), $24-33$. https://ejournal.unib.ac.id/index.php/potensia/article/view/2963

Anggraeni, M., Waluyanto, H. D., \& Zacky, A. (2017). Perancangan Buku Panduan Bergambar tentang Pemanfaatan Daur Ulang Barang Bekas Bernilai Edukasi. Jurnal Desain Komunikasi Visual Adiwarna, 1. https://www.neliti.com/id/publications/86785/perancangan-buku-panduan-bergambar-tentangpemanfaatan-daur-ulang-barang-bekas-b\#cite

Budiono, B. (2017). Pemanfaatan Limbah Botol Plastik Menjadi Prakarya Boneka Pinguin sebagai Bentuk Implementasi dari Pendidikan Lingkungan Hidup. PINUS: Jurnal Penelitian Inovasi Pembelajaran, 2(2), 113-117. http://ojs.unpkediri.ac.id/index.php/pinus/article/view/716

Dewi, N. K. (2018). Pengaruh Alat Permainan Edukatif Barang Bekas terhadap Perkembangan Kreativitas Anak 5-6 Tahun di Raudhatul Athfal Akhlakul Karimah Kotabumi Lampung [Universitas Islam Negeri Raden Intan]. http://repository.radenintan.ac.id/5769/1/Skripsi Full.pdf

Elpia, N., \& Saridewi, S. (2020). Stimulasi Kemampuan Berbicara Anak melalui Media Poster. Jurnal Pendidikan Tambusai, 4(2), 1419-1424. https://jptam.org/index.php/jptam/article/view/607/534

Fadhila, O., \& Rakimahwati, R. (2020). Limbah Daur Ulang dapat Meningkatkan Kreativitas Anak di Taman Kanak-Kanak. Jurnal Pendidikan Tambusai, 445 4(1), https://jptam.org/index.php/jptam/article/view/481/427

Hanafi, S. H., \& Sujarwo, S. (2015). Upaya Meningkatkan Kreativitas Anak dengan Memanfaatkan Media Barang Bekas di TK Kota Bima. Jurnal Pendidikan Dan Pemberdayaan Masyarakat, 2(2), 215-225. https://doi.org/10.21831/jppm.v2i2.6360 
148 Pembelajaran dengan Kegiatan Daur Ulang Botol Bekas untuk Anak Usia Dini-Weni Mulia Putri, Rismareni Pransiska

DOI: https://doi.org/10.31004/edukatif.v3i1.269

Iriani, S. (2013). Meningkatkan Kemampuan Motorik Halus Anak Melalui Kegiatan Menggunting dengan Mengguanakan Bahan Bekas pada Kelompok B TK Widya Merti Surabaya. Jurnal PAUD Teratai, 2(2), 1-11. https://ejournal.unesa.ac.id/index.php/paud-teratai/article/view/2538

Kristanto, V. H. (2018). Metodologi Penelitian Pedoman Penulisan Karya Tulis Ilmiah (KTI). CV Budi Utama.

Maghfirah, S. (2019). Pemanfaatan Barang Bekas dalam Meningkatkan Kemampuan Motorik Halus Anak. Atfālunā: Journal of Islamic Early Childhood Education, 2(1), 48-52. https://doi.org/10.32505/atfaluna.v2i1.938

Mulyati, S., \& Sukmawijaya, A. A. (2013). Meningkatkan Kreativitas pada Anak. Jurnal Inovasi Dan Kewirausahaan, 2(2), 124-129. journal.uii.ac.id > ajie > article > download\%0A

Mursid, M. (2015). Belajar dan Pembelajaran PAUD. PT Remaja Rosdakarya.

Nurani, Y. (2012). Pengembangan Media Daur Ulang Berbasis Kecerdasan Jamak dalam Peningkatan Keterampilan Hidup Anak Usia Dini. Jurnal Cakrawala Pendidikan, 31(1), $67-81$. https://journal.uny.ac.id/index.php/cp/article/view/1467/pdf

Nuwairah, N., Zainuddin, Z., \& Mastuang, M. (2018). Pemanfaatan Barang Bekas dalam Pembuatan Alat Peraga dengan Menggunakan Model Inquiry Discovery Learning Terbimbing. Jurnal Ilmiah Pendidikan Fisika, 2(2), 98-112. https://doi.org/10.20527/jipf.v2i2.1006

Puspitasari, D. (2018). Pengaruh Pemanfaatan Sampah Daur Ulang terhadap Kreativitas Seni pada Anak Kelompok B Raudhotul Athfal (RA) di Kecamatan Gurah [Universitas Nusantara PGRI Kediri]. http://simki.unpkediri.ac.id/mahasiswa/file_artikel/2018/14.1.01.11.0385.pdf

Sugiyono, S. (2013). Metode Penelitian Kuantitatif Kualitatif dan R\&D. Alfabeta. https://doi.org/10.1017/CBO9781107415324.004

Sulaiman, U., Ardianti, N., \& Selviana, S. (2019). Tingkat Pencapaian pada Aspek Perkembangan Anak Usia Dini 5-6 Tahun Berdasarkan Strandar Nasional Pendidikan Anak Usia Dini. NANAEKE: Indonesian Journal of Early Childhood Education, 2(1), 52-65. https://doi.org/10.24252/nananeke.v2i1.9385

Suyadi, S. (2017). Teori Pembelajaran Anak Usia Dini Dalam kajian Neurosains. PT Remaja Rosdakarya.

Wahidah, A. F. N., \& Erni, M. (2019). Upaya Mengembangkan Kemampuan Motorik Halus Anak melalui Pemanfaatan Bahan Bekas dalam Pembelajaran di Kelompok B RA Ar-Rafif Kalasan, Sleman, Yogyakarta. Al-Hikmah: Indonesian Journal of Early Childhood Islamic Education, 3(1), 1-15. http://journal.iaialhikmahtuban.ac.id/index.php/ijecie/article/view/52/37

Wahyuni, I. (2018). Pemilihan Media Pembelajaran. Jurnal Pendidikan, 1(1), 1-11. https://core.ac.uk/download/pdf/160250003.pdf

Wigati, M., \& Wiyani, N. A. (2020). Kreativitas Guru dalam Membuat Alat Permainan Edukatif dari Barang Bekas. As-Sibyan: Jurnal Pendidikan Anak Usia Dini, 4(1), 43-56. https://doi.org/10.32678/assibyan.v5i1.2700

Zaman, B., \& Eliyawati, C. (2010). Media Pembelajaran Anak Usia Dini. In Bahan Ajar Pendidikan Profesi Guru $\quad(P P G)$. http://file.upi.edu/Direktori/FIP/JUR._PGTK/197010221998022CUCU_ELIYAWATI/MEDIA_PEMBELAJARAN_ANAK_USIA_DINI-PPG_UPI.pdf 